\section{Clinital aifecture}

\author{
or
}

\author{
ME DULLO - A R THRITIS. \\ By J. GREIG SMITH, M.A., \\ SURGEON TO THE BRISTOL ROYAL INFIRMARY.
}

Gentremen,-To-day I wish to direct your attention to the distinctions between the two forms of so-called white swelling of joints, and specially to illustrate the progress and treatment of one of the forms by the two cases now before you. These chronic joint inflammations have long been called strumous, and I believe with justice. One commences as an inflammation of the synovial membrane, the other as an inflammation of the pink marrow in the cancellated ends of the long bones; and both ultimately proceed to disintegration of all the structures entering into the articulation. The first might conveniently be called "synovio-arthritis," the secoad "medullo-arthritis." You will understand the clinical differences between the two diseases more readily if I shortly describe to you their pathology. And, first, as to "medullo-arthritis."

You are aware of the fact that the pink marrow in cancellous bone belongs to the lymph-glandular class of organs, and probably discharges most of the functions of ordinary lymphatic glands. You are also aware that in a certain habit of body called "strumous," the lymphatic tissues are liable to a peculiar form of inflammation. This form of inflammation is characterised by its chronicity, and by a tendency for its products to retrograde and undergo the form of degeneration called "caseation." The similarity as to structure and function between pink marrow and lymphglandular tissue in health is still further borne out in disease. Wherever we find pink marrow, in the ends of the lono bones, in the bodies of the vertebræ, in the bones of the hands and feet, there we frequently find it affected with a form of inflammatory disease similar to that found in the strumous diseases of lymphatic glands in connective tissue. The inflammatory products are of the same histological type; they show the same sluggishness, and have a like tendency to undergo the caseous metamorphosis. Thus far the likeness is complete, but hereafter there are important divergences.

A strumous lymphatic gland in the neck has room to swell, and, if it suppurates, its contents perforate the skin, and so are discharged from the system. But it is not so with the bone glands. They are bound down inside a bony shell, and the swelling, which is a sequence of the inflammatory process, results in compression and strangulation. But the inflammation proceeds, and the inflamed, perhaps suppurating, tissues force an outlet wherever they most easily can. In the bones of the hands and feet the compact shell is thinnest on the dorsal aspects, and there we find the opening. In the vertebræ the perforation fortunately takes place on the anterior aspect. But in the ends of the long bones the inflamed marrow usually takes the most dangerous coursethrough the articular cartilage into the joint cavity. Elsewhere the terminations are often serious enough; but here the results are peculiarly grave. When the marrow abscess - for so it may be called-bursts into a joint a form of suppurative synovitis is set up, which, if untreated, will infallibly lead to complete destruction of the articulation, perhaps

1 We have in our medical vocabulary no single term to express that form of chronic joint disease which commences as an inflammation in the cancellated tissue of bone. "Osteo-arthritis" would perbaps have been the most suitabie name, but this has unfortunately been already made use of as a synonym for the rheumatic form of chronic joint dis ease. I say " unfortunately," because whatever else chron1c osteoarthritis, usually so called, may be, it certainly is not primarily or essentially, as its name would imply, an inflammation of the bones in the neighbourhood of a j3int. Among our best anthorities-notably, Macnamara, Barwell, and Bryant-there is no want of outspokenness as to the radical differences between the synovitic and the ostitic forms of strumous joint disease. It may not therefore be premature to attempt to give them separate names. Partly because the terin "osteo-arthritis" is not artilable, but chiefly because the inflammation is one of marron rather than of bone, I would call the disease starting in the cancellated ends of the long bones "medullo-arthritis." The other disease migh then he named "synovio-arthritis." I believe that such a nomenclature, oy calling prominent attention to their undoubted differences in origin and progress, would bo beneficial as regards botb science and practice. Lio. 3012 even to loss of the patient's life. With the most skilful treatment the disease is always grave; indeed I should probably be correct in suying that it is our most prolific source of amputations of the thigh.?

The other form of strumous arthritic dizease is primarily and essentially one of the synovial membrane. What is the special pathological feature of the disease I cannot here stay to discuss. Suffice it to say that the synovial tissne is trans. formed into a pulpy gelatinous-looking material which is always cedematous, and snmetimes, especially in the more advanced cases, infiltrated with collections of caseous or purulent matter. 'Histologically the structure is lymphadenoid; and frequently we find it infiltrated with tubercles, or at least with globular aggregatious which receive that name. I show you some specimens in which great numbers of the so-called tubercles can be seen. Note the beautifully regular concentric arraugement of the cells in these bodies. They are rounded in the centre, flattened and tailed at the periphery, suggesting the structure of a covcentric globe in epitheliona. Very likely these ought to be classified as tubercles; individually I believe they are lymphatics which have become blocked by the proliferation of their endothelium. It is, I think, probable that lymphatic obstruction is an important element in the causation of the disease. The amount of oedema and the abundance of immature and degenerate lymph cells present in every case lend a high probability to such a view.

This lowly organised pulpy granulation-tissue is endowed with a peculiar tendeney to infect, or ab:orb, or assimilatecall it what you will - every form of fibrous tissue which it meets. The tendinous structures in and around the joint always suffer, and the fungating tissue creeps on from the periphery over the articular cartilage, corroding and absorbing or transforming it in its course. By-and-by the synovitic material completely eats through the articular cartilage, and, so to speck, taps the marrow cavity. In the pink marrow it meets with a tissue most congenial for infection, and matters now proceed apace to the complete disintegration of the joint.

Such is a short résumé of the natural history of the two forms of disease. Let me now, by the help of these preparations, contrast them more in detail.

Here are three specimens of knee-joints affected with medullo arthritis. Note in the first place the slight amount of synovial thickening. In each you see that the articular cartilage on the end of the femur is perforated at several points, and that around each perfuration the cartilage is everted and thinned out from below. Here and there a piece of cartilage is elevated like a blister ; there perforation by fungating marrow is about to take place. At one part a mass of granulation material protrudes from the end of the femur under the patella, and the opposing patellar cartilage is corroded on its surface. The same may be seen on the head of the tibia where a corroded area was in contact with anotber mass of protruding granulations.

In contrast with these note the appearaces in these joints affected with synovio-arthritis. There is enormous thickening of the synovial tissue. In all the joint cavity is lessened, in some almost completely obliterated, by the inward growth of the gelatinous pulpy tissue. By lifting up the diseased material from the cartilage you can see how it is corroded and eaten away under it. This fresh section shows the gradual growth inwards over the joint surface, and the progressive absorption of the articular cartilase. Everywhere the cartilage is corroded on the surface; nowhere is it perforated from below. Here, where the marrow cavity has been tapped, you can see nothing of the eversion of the edyes of cartilage which you see in the other specimens. The crucial ligaments in one specimen are so completely infected and transformed that you can see a series of granulation tufts sent out from them to eat up the cartilage over the condyles. I peel these off, and the corroded cartilage is perfectly sound and firmly adherent to the bone beneath.

You are now in a position more readily to understand the clinical distiuctions between these two diseases. In the synovial disense there is little hyperæmia, and except in the advanced stage little pain. Even when there is some abrasion of the cartilage, the flabby anæmic granulations, packed between the denuded surfaces, act as buffers and prevent pain. Grating inside a joint is supposed to mean "ulceration of cartilage," but, as has often been pointed out

A detailed account of the writer's views on this subject is given in the Bristol Royal Infirmary heports for 1878-79. 
to you, there may be much abrasion without any grating when masses of synovial granulations serve to separate the articular surfaces. A joint may be far advanced in synovial disease, and still be used in movement or walking without causing much pain. Perhaps the most important diagnostic fact in synovial disease is that until in the last stages, when these pulpy granulations have broken down and suppurated, there is no "starting" in the joint as the patient drops off to sleep.

In medullo-arthritis, a vain, where we have a highly sensitive and vascular organ compressed inside a bony shell, there is tenderness during, and great dread of any sharp movement. Percussion around the joint causes pain. Long before the cartilage is perforated the patient is a cripple, and when the marrow has forced its way through, and a suppurative synovitis is added to the osteo-myelitis, there is always great pain, often extreme agony. The exposed cancellated bones rubbing on each other must be credited with this. Here the synovial thickening is not enough to prevent the raw surfaces from grating. It is in this disease by preeminence that we get nocturnal startings.

On inspection and palpation differences may be detected. A joint affected with synovio-arthritis has pale, smooth, sometimes glassy and lustrous skin, and large blue, but somewhat deeply set, veins coursing over it. In medullo-arthritis the skin is not pale, but of an obscure dingy red; instead of being smooth, it is usually rather rough and mottled, and is frequently covered with long hairs from the patient keeping it at rest under his clothing on account of the pain.

When the synovial membrane becomes fully implicated we may, however, find a close resemblance to pure synovioarthritis. The peculiar sensation of bogginess in a synovitic is not present, or is less marked in an ostitic joint. Brawniness in the earlier stages, at least, would better characterise the condition in the latter form. Generally we might say that stiffness and dread of movement were characteristics of the ostitic disease. In both cases, from softening of ligaments, there is undue lateral mobility.

Such are the leading clinical distinctions between the two diseases. Euch case must be judged by itself, and this you have dailv upportunities of doing in our wards. When abscesses hru formed and sinuses exist, you may conclude that the two diseases co-exist; but you should still endeavour to find out whether marrow or synovial membrane was the original cause, and direct your treatment accordingly. (To be concluded.)

\section{THE PATHOLOGY AND ETIOLOGY OF MYXCEDEMA.}

BY F. A. MAHOMED, M.D.,

PHYSICIAN TO THE LONDON FEVER HOSPITAL AND MEDICAL REGISTRAR TO GUY'S HOSPITAL.

IT is undoubtedly important that we should recognise clinically that interesting group of cases presenting the peculiar condition now known as myxodema ; but it is also desirable that before regarding the condition as a new disease we should first ascertain whether or not it may be a somewhat rare complication of one or more with which we are already acquainted.

When these cases come before us our first supposition is that we have to deal with a renal dropsy. It is only on more careful examination that we are inclined to abandon this diagnosis when we find the urine normal, the apparent cedema solid, and certain nerve symptom * present. We then recall the condition described by Sir Wllliam Gull as a "cretiuoid state supervening after adult life in women," and subsequently so carefully investigated by $\mathrm{Dr}$. Ord, who gave it the name of "myxœlema." Since those pupers were written severd other cases have been reported by various writers, some proving fatal. The evidence afforded by these cases, and by others which have fallen under my ob. servation, seems to warrant the belief that this condition is one of chronic and organising odema, oceurring most frequeutly in the subjects of chrnic Bright's disease, and occasionally in other more rare couditions.

In a papar about to appear in the Guy's Hospital Reports

have collccted together a large number of cases which appear to prove the very frequent existence of chrunic
Bright's disease without albuminuria. Among them were no less than twelve who suffered from well-marked renal dropsy, the urine, though examined daily in most of the cases, being always, or nearly always, normal. Albumen was present in three out of the twelve cases, and on only one or two occasions in each of these three. Two of these cases (Cases 31 and 32 in the paper referred to) appear to me to throw much light upon the condition known as myxodema. One of them, which proved fatal, was under the care of Dr. Wilks; the other was under my own care as an out-patient. In these two patients the cedema was chronic, and, like that of this disease, did not retain the im. pression of the fingers; they had also the characteristic condition of the nervous system. This was especially developed in one of them which proved fatal. The condition, though not extreme in either case, was very well marked. In both of these cases, although the urine was not albuminous, the arterial pressure was very high; well-marked displacement of the apex beat was made out in the fatal case, and extensive retinitis in the other. I was therefore led to regard them as cases of chronic Bright's disease without albuminuria. The fatal case had albuminous urine two days before death. The heart was found to weigh fifteen ounces; the vessels were much thickened; the kidneys, however, except for the thickening of the arterioles, proved to be perfectly normal; they weighed eleven ounces. The liver showed well-marked intercellular fibrillation. Dr. Goodhart, who made the post-mortem examination, regarded the case as one of myxoedema, but no excess of mucin was found in the dropsical tissues, which were carefully examined by Dr. Stevenson.

In applying the term chronic Bright's disease to cases of myxoedema, I have employed it in its most extended sense-that is, as including those cases described by Sir William Gull and Dr. Sutton as arterio-capillary fibrosis, in which the cardio-vascular changes are present, though the kidneys may or may not be granular. I have maintained in the paper alluded to and elsewhere, that the majority of these cases have normal urine; they die by failure of the heart or lungs, by cerebral hremorrhage, and in many other ways. About 30 per cent. die of nephritis, and these are the cases in which albumi. nuria is present, and that are most frequently recognised as cases of chronic Bright's disease. But in many of the others albuminuria, if present, is a transient symptom, which comes and goes with variations in their health, exposure to cold, and stomach disorder, \&s. It is as part of this disease that I have regarded these two cases.

Let us now turn to the published cases of myxoedema recorded by Sir William Gull, Dr. Ord, and others. I have been able to collect from the Transactions of the Clinical Society, and from Dr. Ord's paper in the MedicoChiruroical Society's Transactions for 1878, a considerable number of examples of this condition; they amount to twenty in all. In several of these the observations on the urine are by no means frequent; but it is noted that no less than ten had albumen present in small and variable quantities, and four of these cases proved fatal; in three of them post-mortem examinations were made, and all of these had hypertrophied hearts, thickened arteries, granular, and more or less contracted, kidneys. In Dr. Ord's first case the kidneys weighed nine ounces and a half, the "substance of organs somewhat firm, slightly tough, and both surface and section granular. Curtex generally but uniformly wasted, and its arrangement not much distorted; it contains a few small cysts. Minute arteries in kidneys generally considerably thickened. Renal arteries much thickened, and very atheromatous; the outer coat also apparently thickened." The duaving of the mitroscopical appearances of this kidney, published in the same paper, shows in an extreme degree what mxy be called the vascular changes produced in the kilneys of Bright's disease; there is very great fibro. hyaline trickenmg of the Malpighian capsules, of the arterial coats, and the intertubular connective tissue. The heart weighed sixteen ounces and a hrili.

In Dr. Ord's second case" "the Kidneys were of average size and of extsaordinary firmness, giving to the touch a seasation like india-rubber. The surface was smootb, the capsules non-adberent"; but under the microscope "the encroachments of connective tissue in the intertubular region, in the walls of the Malpighian bodies, around the vessels of the tufts, and around the arteries, are very obvious.

1 Med.-Chir. Soc. Trans., 1878. 2 Clin. Soc. Trans., 1Sso. 